\title{
PRÁCTICAS ALIMENTICIAS EN UNA COMUNIDADAD QUILOMBOLA DE LA AMAZONIA BRASILEÑA
}

\author{
Marcilene Silvada da Costa \\ marcicosta@hotmail.com \\ Doctorante en Antropología Social e Historia \\ Universidad de Toulouse 2 Le Mirail-UTM-LISST-CAS
}

\section{RESUMEN}

Se trata de un trabajo sobre las prácticas de alimentación de los habitantes de una comunidad quilombola (descendientes de esclavos cimarrones) de la Amazonia brasileña. Los residentes de esta comunidad, apoyados por una asociación comunitaria local, reivindican la tenencia de la tierra en la que viven, defendiendo el hecho de ser descendientes de los antiguos habitantes de los quilombos (viviendas de los esclavos cimarrones), de conformidad con el Artículo 68 de la Constitución Federal brasileña de 1988. Las tierras donde viven son zonas rodeadas por haciendas ganaderas pertenecientes a grandes terratenientes y hombres influyentes en la vida política de la región. Esto significa que los quilombolas cuentan con un espacio reducido para la agricultura familiar, base antigua de sus actividades económicas, lo cual lleva a que muchos de ellos deban abandonar estas prácticas agrícolas para trabajar en las haciendas vecinas o en las ciudades. Generalmente, los hombres como peones y las mujeres en el servicio doméstico. La consecuencia es la reducción de la proporción de los alimentos producidos localmente, que provoca un cambio en el estilo de vida y en el consumo de alimentos, que cada vez más son comprados en el mercado; se efectúan, de esta manera, cambios en las representaciones y en las prácticas de alimentación cotidiana.

Palabras claves: Amazonia brasileña, comunidades quilombolas, prácticas de alimentación, alimentos. 


\section{ABSTRACT}

This is a work on the inhabitants of a community feeding practices quilombola (descendants of runaway slaves) of the Brazilian Amazon. The residents of this community, supported by a local community association, claimed possession of the land on which they live, defending the fact of being descendants of the ancient inhabitants of the quilombos (runaway slave dwellings), in accordance with article 68 of the 1988 Brazilian Federal Constitution. The land where they live are areas surrounded by cattle farms belonging to large landowners and influential men in the political life of the region. This means that the quilombolas have a space for family agriculture, former base of their economic activities, which means that many of them need to abandon these agricultural practices to work on neighbouring farms or cities. Generally, men as pawns and the woman in domestic service. The result is a reduction in the proportion of foods produced locally, that causes a change in the style of life and consumption of foods, which increasingly are purchased in the market; changes are made, thus in the representations and the daily feeding practices.

Key words: Brazilian Amazon, Quilombola communities, feeding practices, food. 


\section{LA COMIDA DE LOS QUILOMBOLAS}

En el presente trabajo se pretende dar cuenta de las prácticas alimenticias, desde una perspectiva socio-antropológica, de los habitantes de una comunidad quilombola (descendientes de esclavos cimarrones) en la Amazonia brasileña. El objetivo es centrarse en las observaciones de campo sobre la alimentación quilombola y la percepción que los niños locales tienen sobre los alimentos producidos y consumidos localmente.

Muchos estudiosos argumentan que, a través de los hábitos alimentarios, una sociedad o un grupo social se expresa y comunica. Debido a que estos pueden utilizarse para comprender e interpretar una determinada realidad (Bonim y Rolim, 1991).

De acuerdo con Torrão (1995), la alimentación no solo está determinada por factores climáticos o geográficos, ya que en el establecimiento de una dieta alimenticia intervienen elementos psicosociológicos que la marcan y definen. El alimento, además de ser una sustancia nutritiva que sirve para la manutención física de las personas, contiene también código de valores y símbolos propios.

\section{LA REIVINDICACIÓN DE TÍTULOS DE PROPIEDAD COLECTIVA DE LA TIERRA}

Basados en la memoria colectiva local, los habitantes de Boa Vista do Ita, representados por la asociación de la comunidad del lugar, reivindican actualmente la titularidad de las tierras donde viven. Para ello alegan habitar en una comunidad de los descendientes de esclavos cimarrones de conformidad con el Artículo 68 de la Constitución Federal Brasileña de 1988, que dice: «los descendientes de las comunidades de los quilombos ${ }^{1}$ que estén ocupando las tierras, estas deben ser reconocidas como propiedad definitiva, debiendo el Estado emitirles sus respectivos títulos». ${ }^{2}$ 
El origen del término quilombo se remonta a la época colonial y fue elaborado por el Consejo de Ultramar en 1740 para definir la vivienda de los negros fugitivos de la esclavitud. Sin embargo, gracias al Artículo 68, revisado actualmente, este término recibe una nueva significación y puede designar: « La situación de los segmentos de negros en las distintas regiones y contextos en Brasil, haciendo referencia a tierras que resultaron de la compra por negros libertos; de la pacífica posesión por esclavos de tierras abandonadas por los propietarios, en época de crisis económicas ; la ocupación y administración de las tierras donadas a los santos patronos de la tierra o entregadas o compradas por los antiguos esclavos organizados en quilombo (palenques o cumbes)». ${ }^{3}$

De tal forma, como mencioné anteriormente, los residentes de Boa Vista del Ita, en 1999, con la asistencia de representantes de una entidad urbana del movimiento negro de Belém y de investigadores de la Universidad Federal de Pará, junto al Instituto de Tierras del Pará (ITERPA), ${ }^{4}$ comenzaron el proceso de legalización de tierras en la comunidad como descendientes de quilombos.

La zona en litigio es de 1,210 hectáreas donde un 90\% de ellas están tituladas a favor de terceros. De acuerdo con la memoria local, las tierras que habitan han sido donadas por un caballero francés llamado Major Santos a su pareja de esclavos, Felipe Mariano dos Santos y María Madalena de Fonseca, pareja que dio origen a la ubicación actual.

Según Conde (1999), Major Santos posiblemente emigró a esta región, a través del sistema de donación de las sesmarias (asignaciones o mercedes de tierras), durante el gobierno imperial de principios del siglo XVIII. A lo largo del río Caraparu, principal de la región, se ha registrado la concesión de varias sesmarias.

El comandante Major dejó a la pareja de esclavos el equivalente a 2,000 hectáreas de tierra donde el pueblo se desarrolló. El Boa Vista del Ita de hoy se compone de 33 familias (156 
personas), donde casi la totalidad, exactamente 30 de las familias, tiene el primero o segundo apellido «dos Santos»; ${ }^{5}$ sabemos que en la época de la esclavitud los señores bautizaban a los esclavos con el nombre de su propia familia, era una práctica común. El apellido «dos Santos» es bastante frecuente también en las comunidades de los alrededores.

Las tierras donadas por Major dos Santos (2,000 ha) se redujeron a 12 ha a causa de la venta de las mismas por los familiares de los residentes actuales; e incluso fueron vendidas por los organismos gubernamentales (INCRA) y (ITERPA) como terrenos baldíos a dos grandes terratenientes en la década de los ochenta del pasado siglo. Algunos residentes recuerdan que sus familiares intercambiaron grandes extensiones de tierra por el equivalente de una canasta básica de alimentos. Así es que, hoy, se encuentran en una situación de extrema precariedad, sin tierra para plantar, completamente rodeados por haciendas ganaderas.

\section{UBICACIÓN DEL BOA VISTA DEL ITA}

Boa Vista del Itá es un pueblo situado en el municipio de Santa Isabel do Pará, distante 60 kilómetros de la capital del Estado do Pará, Belém, Brasil. Ubicado, precisamente, en el distrito Caraparu. El municipio de Santa Isabel do Pará cuenta con tres distritos: Caraparu, Americano y la sede del municipio. Boa Vista del Ita se asemeja a varios otros pueblos localizados a lo largo de las orillas del río Ita, uno de los brazos del río Caraparu; uno de los rasgos comunes de estas comunidades es el hecho de ser un pueblo negro rural.

El historiador Figueiredo dice que en 1888, año de la abolición de la esclavitud en Brasil, el Caraparu ${ }^{6}$ se constituyó apenas en un pequeño pueblo, donde vivían los descendientes de esclavos cimarrones, especialmente de Belém. Para el mismo autor: «Caraparu fue el nombre dado a un quilombo, poco conocido que existía en las cercanías de Belém, durante la primera mitad del siglo XIX» (1996:178). 
Según Salles (1988), en uno de los brazos del río Guamá, en el río Caraparu, había un mocambo ${ }^{7}$ formado por cabañas distribuidas en la zona, localizado en las márgenes del arroyo Itá. Por esta razón, la región del río Guamá fue el objetivo de frecuentes «batidas» de la policía, ya que estaban constantemente en busca de quilombos, con el fin de destruirlos y detener a los negros que los habitaban.

\section{METODOLOGÍA DE TRABAJO}

El trabajo de campo tuvo lugar durante el mes de agosto 2009. Estuve en Boa Vista acompañada por una estudiante de derecho de la Universidad Federal do Pará, en el marco del proyecto «Cuerpo Presente». ${ }^{8}$ Los primeros días fuimos al encuentro de los habitantes para explicarles el objetivo de la investigación y hacer un diagnóstico de la situación socioeconómica y alimenticia.

La aplicación de formularios nos permitió tener un panorama general sobre los perfiles socio-económicos y las prácticas alimenticias. Pero lo más importante de ese momento es que nos ha permitido establecer los primeros contactos con los habitantes. Esto nos facilitó identificar a los interlocutores potenciales para las entrevistas sobre las memorias y las historias de la comunidad.

Decidimos colectar los datos por medio de entrevistas abiertas, utilizando una grabadora y redactando las observaciones en un diario de campo. Utilizamos también la técnica de «historias de vida», la cual fue fundamental para llamar y recuperar los recuerdos. Efectivamente, los narradores, hablando sobre ellos mismos, nos relatan también de las relaciones sociales, de la historia local y finalmente del contexto en el cual están insertos (Debert, 1986). Hicimos cinco entrevistas abiertas y cuatro historias de vida con habitantes adultos de la comunidad. 
Bosi (1994) afirma que cuando uno trabaja sobre la memoria, el registro de los recuerdos se extiende más allá de la memoria personal, individual, y uno está tratando con una memoria social, familiar y colectiva.

También llevamos a cabo talleres con niños sobre las representaciones de la identidad del cuerpo, salud y alimentación -a través de dibujos y pinturas. El taller contó con la presencia de 23 niños, en la franja de edad entre dos y doce años. Esto se hizo durante una mañana. Allí les pedimos que dibujaran los alimentos que consumen a diario. Habíamos aprovechado el momento del diagnóstico para informar de la realización de estos talleres. La totalidad del material presentado en este artículo ha sido colectado por M. R y la autora, en el cuadro del proyecto «Cuerpo Presente».

\section{ACTIVIDADES ECONOMICAS DE LOS HABITANTES DE BOA VISTA}

Boa Vista del Ita se considera un pueblo de agricultores; sin embargo, algunos cambios debidos a la restricción de las tierras obligaron a varios de los habitantes locales a cambiar sus actividades económicas y, en consecuencia, también las prácticas alimenticias. El cambio más importante es que ahora están obligados a comprar la mandioca -producto de base de sus actividades económicas--, y esto es debido a la reducción de las tierras cultivadas.

De acuerdo con la memoria local, en la antigüedad había una menor dependencia de los mercados; plantaban, pescaban y producían para el consumo propio, de forma que todas las familias trabajaban en la agricultura local. En la actualidad, este marco ha cambiado, ya que algunos de ellos tienen otras actividades económicas que no están relacionadas con la agricultura. Sin embargo, a pesar de las dificultades causadas por la falta de tierra para cultivar, la ocupación principal sigue siendo la agricultura. 
En la actualidad, según el censo realizado en 2009 en la comunidad, de las 156 personas encuestadas, 62 trabajan en alguna actividad específica de la agricultura. En el ámbito profesional, la actividad que más se destaca es el trabajo en los campos, 50 personas respondieron que desarrollan esa actividad (véase Tabla 1).

Tabla 1. Actividades económicas.

\begin{tabular}{|l|c|}
\hline \multicolumn{1}{|c|}{ Actividades económicas } & Número de personas \\
\hline Trabajo en los campos & 50 \\
\hline Trabajo en la huerta & 12 \\
\hline Empresa avícola & 10 \\
\hline Servicios generales & 5 \\
\hline Jubilación & 34 \\
\hline Estudiantes & 24 \\
\hline Niños de menos de siete años & 4 \\
\hline Empleadas domésticas & 3 \\
\hline Cuidadores de residencias & 6 \\
\hline Cuido de mis hijos a jornada completa & 3 \\
\hline Funcionario & $\mathbf{1 5 6}$ \\
\hline Total de personas & \\
\hline
\end{tabular}

Fuente: Trabajo de campo, 2009

Por lo tanto, es evidente que, a pesar de las dificultades, la base de la economía continúa siendo el trabajo en la granja para la producción de harina de yuca, seguido del trabajo en la huerta en el cultivo de verduras y legumbres (doce personas). Cabe destacar que gran parte de las personas que respondieron que tenían como actividad principal labores agrícolas estaban asociadas a una actividad secundaria, como producción de carbón vegetal y servicios generales. 
El grupo familiar es responsable de la producción y comercialización de los productos. Aunque el número de personas que trabajan en la agricultura es predominante. Otros diez residentes trabajan en la empresa avícola Frango Americano (pollo americano), situada a unos seis kilómetros del pueblo.

El trabajo que se ejerce en la empresa se ubica como mano de obra no calificada; la mayoría de estas personas tienen horarios nocturnos, ya sea en la descarga pollos de los camiones, como ayudante del sacrificio de pollos o en el servicio de embalaje de los productos. Algunas otras actividades se destacan, como por ejemplo: servicios generales (cinco personas), particularmente como mano de obra no calificada al servicio de los terratenientes.

Existen cinco personas que se benefician de la jubilación como trabajadores rurales, lo que significa una renta segura - bastante considerable puesto que equivale a un salario mínimo - para la familia de los jubilados. Renta significativa que asegura la compra mensual de alimentos para una familia entera. Existen más personas en edad de jubilarse, pero no pueden hacerlo porque carecen de los documentos necesarios para realizar trámites, como el documento de identidad e incluso el acta de nacimiento.

Una gran parte de la población es bastante joven (34 personas), se trata de niños con más de siete años que van a la escuela y que han sido considerados por nuestro censo solo como «estudiantes», cuando en realidad ellos ayudan generalmente a sus padres en el campo después de la escuela. Las otras (24 personas) son niños menores de siete años que todavía no asisten la escuela.

Hay cuatro mujeres que trabajan en la sede del distrito de Santa Isabel, como empleadas domésticas para tener la oportunidad de asistir a la escuela secundaria, debido a que la matrícula escolar es el acceso a la enseñanza primaria en una escuela cercana. 
La entrada a la escuela solo es posible en la ciudad, pero el municipio no ofrece el servicio de transporte público; los pocos que se aventuran a estudiar están obligados a trasladarse en bicicleta aproximadamente treinta kilómetros en la madrugada para llegar a clase a tiempo. Conscientes de que en el regreso a casa, o al trabajo, les tocará ayudar a los parientes en la fabricación de la harina de yuca.

Las mujeres que trabajan como empleadas domésticas lo hacen a cambio de comida y estudio. No reciben siquiera un salario mínimo o, a veces, una cantidad irrisoria; no es preciso decir que no tienen contrato laboral.

Otra realidad es la de tres personas que se dedican a la función de cuidadores de residencias o propiedades, vigilan y cuidan las casas o terrenos de los propietarios, quienes a menudo son de ciudades lejanas y han comprado tierras en la localidad como su residencia de descanso en fines de semana, días festivos y vacaciones. También es posible llevar a cabo la actividad de cuidador de casas en otros lugares; por ejemplo: el padre de una de las personas es cuidador de casa, se ocupa de un terreno en el pueblo de Bujaru y tiene derecho a tiempo libre una vez al mes para visitar la comunidad.

Aunque gran parte de la población de la comunidad trabaja en las granjas y en la fabricación de harina de yuca, la mayoría de las familias se ven obligadas a comprar yuca a terceros. La disponibilidad de terrenos para cultivar es realmente muy restrictiva.

Las familias compran el saco de yuca en 8 dólares; en tanto que venden el saco de harina de yuca ya elaborada, lista para consumir, en 43 dólares. Un saco de harina equivale a una semana de trabajo de toda una familia. También venden otros productos extraídos de la yuca, por ejemplo: el tucupi (líquido amarillo extraído de la yuca fresca) y la goma (almidón de yuca). Antes hacían solo la harina, pero a través de un taller impartido por una fundación denominada «Curro Viejo de la Comunidad»-Institución Pública del Estado- 
aprendieron la fabricación de almidón y tucupi.

Las familias hacen harina de yuca una vez a la semana. Hombres y mujeres cosechan juntos y transportan la yuca comprada. Hay, más o menos, siete molinos de harina en la comunidad, pero solo uno es utilizado por la mayoría de los residentes. Los otros seis molinos solo son usados por sus propietarios. El trabajo de preparación de la harina de yuca requiere la participación de toda la familia, tanto adultos como niños.

En general, se divide así: los hombres tuestan la harina, las mujeres sacan el tucupi, los niños criban la masa y los adolescentes rallan la yuca. Aunque tostar la harina se considera una obra típicamente masculina, a veces las mujeres también lo hacen.

El molino de harina, además de ser un espacio de producción, puede considerarse también un espacio de sociabilidad. La gente en el trabajo conversan, se ríen y se divierten: contando cuentos, chistes, chismes, haciendo comidas, transformando el trabajo en una gran reunión familiar.

Antes de que existiera la carretera, la producción agrícola era transportada en canoa por el río Ita hasta el río más próximo de mayor importancia, el Caraparu, o hasta el Guama, que conducen a Belém. Los viajes duraban de uno a tres días, dependiendo del uso de canoa a remo o a motor. Hoy en día, la existencia de la carretera ha facilitado el traslado de productos. Existe un camión del ayuntamiento que pasa los sábados por la madrugada para llevar los productos y productores a la feria municipal de los agricultores. Llegan a la ciudad alrededor de las 5 de la mañana y venden la mercancía en la acera de la feria. ${ }^{9}$ La falta de un espacio estable para la venta de los productos de los agricultores, al interior de la feria, implica que los vendan de manera informal. Algunos, a causa de esta dificultad, prefieren ofrecerlos a precios irrisorios a los intermediarios, lo que significa que prácticamente casi no tienen margen de beneficio. 
La venta de los productos genera 40 dólares como máximo y 10 como mínimo de ingreso semanal por familia. Con el dinero de las ventas ellos compran alimentos para la semana: frijoles, arroz, pasta, carne, jugos artificiales, entre otros.

El ingreso mensual de los residentes de Boa Vista del Ita oscila entre 110 dólares y 2,750 dólares. Aunque debe decirse que la única persona que recibe los 2,750 dólares no es originario de allí. Se trata de un hombre de la ciudad de Belém que se retiró de la marina mercante y por miedo de la violencia de la gran ciudad se trasladó a Boa Vista del Ita (véase Tabla 2, sobre los ingresos mensuales familiares).

Tabla 2. Ingresos familiares mensuales.

\begin{tabular}{|l|c|}
\hline \multicolumn{1}{|c|}{ Ingresos por família } & Total de familias \\
\hline Menos de 1 salario mínimo & 11 \\
\hline 1 salario mínimo & 5 \\
\hline + 1 salario mínimo & 9 \\
\hline 2 salarios mínimos & 1 \\
\hline +2 salarios mínimos & 2 \\
\hline 3 salarios mínimos & 1 \\
\hline +3 salarios mínimos & 4 \\
\hline Total de familias & $\mathbf{3 3}$ \\
\hline
\end{tabular}

Fuente: Trabajo de campo, 2009.

La media de las familias recibe menos de un salario mínimo por mes. ${ }^{10}$ De las 33 familias, 14 obtienen ayuda del gobierno federal en forma de subsidio. Los valores oscilan entre 67 dólares y 17 dólares al mes. En algunos casos es la única fuente de ingreso estable. 
Debido a la falta de espacio para plantar, el ingreso monetario termina siendo el principal medio para la compra de alimentos; es decir, las familias son más dependientes del mercado de los alimentos, pero, como hemos visto, los bajos ingresos que obtienen las limitan para comprar barato y con poca variedad de alimentos, además de ser insuficiente para alimentar a toda la familia. Algunas veces, cuando se encuentran sin dinero para comprar alimentos al contado en la feria o en supermercados de la ciudad, acaban obteniendo cestas de alimentos a crédito o a un vendedor que ofrece sus productos en un camión que pasa por la comunidad. Sobra decir que se trata de productos caros y de dudosa calidad.

En la compra de estos alimentos, la elección se hace por los mejores precios y no por la mejor calidad. Esto significa que acaban consumiendo alimentos con gran cantidad de sodio y conservantes, los cuales provocan perjuicios a su salud.

\section{LA PROMESA DEL GOBIERNO: SEGURIDAD ALIMENTARIA}

El tema de la alimentación apareció de manera más relevante en la agenda de la política brasileña, desde el gobierno de Lula da Silva (ex-presidente de Brasil), con el lanzamiento en 2001 de la política de seguridad alimenticia, titulada programa «Hambre Cero». Igualmente, en 2003 fue creado un ministerio específico para combatir la pobreza y el hambre (Ministerio Extraordinario de Seguranza Alimentar e Combate à Hambre -MESA). El programa fue diseñado para promover la acción y proporcionar seguridad alimenticia y nutricional para todos los brasileños. Este ministerio fue incorporado, un poco más tarde, en 2004, al nuevo Ministerio de Desarrollo Social y Combate al Hambre (MDS).

El programa «Hambre Cero» fue considerado por sectores de la sociedad civil como uno de los mayores fracasos del gobierno Lula, debido a que no alcanzó los principales objetivos que se había propuesto: acceso a los alimentos para las familias pobres y fortalecimiento de la agricultura familiar. Brasil continúa teniendo unas cifras desoladoras: la pequeña 
propiedad -considerada como la de superficie inferior a 10 ha- representa solamente el 2.7\% del conjunto de establecimientos rurales, mientras que las grandes propiedades rurales de 1,000 ha representan 43\% de ese conjunto. En 1995, la cría de ganado ocupaba 73\% del espacio agrícola y no hubo cambios significativos desde entonces, puesto que ningún programa de reforma agraria fue puesto en práctica (Cunha, 2010).

Según Beraldo (2006), los proyectos y políticas públicas orientados a la construcción de la seguridad alimenticia de Brasil están vinculados a las acciones y programas internacionales, y tienen como principal fuente de financiación el Banco Mundial. Tal política forma parte de uno de los ocho Objetivos del Milenio del Programa de las Naciones Unidas, para reducir la pobreza extrema y el hambre en todo el mundo.

Este programa internacional considera de atención especial la población rural, principalmente indígenas y quilombolas. En la Tercera Conferencia Nacional de Seguridad Alimentaria y Nutricional, celebrada en 2007, fue adoptado un sistema de cuotas para que los representantes de estos dos grupos poblacionales tuviesen una amplia participación en las salas de seminarios, conferencias federales y estatales sobre el tema de la seguridad alimenticia y la nutrición. Esta medida se adoptó debido a que los indígenas y quilombolas son quienes más sufren inseguridad alimenticia en el país.

En el diseño de seguridad del gobierno, alimentar es el derecho al acceso regular y permanente a alimentos de buena calidad y cantidad, sin poner en peligro otras necesidades esenciales de la persona.

El reclamo de tierras de parte de los quilombola unió a varios residentes de Boa Vista del Ita a través de los programas sociales del gobierno. El más importante de estos es la Bolsa Familiar, programa de políticas públicas de transferencia de ingresos en forma de ayuda financiera a las familias que tienen niños inscritos en escuelas públicas. Este programa es universal y no específico de los negros cimarrones, sino que va destinado a todas las familias que viven en pobreza extrema, con un ingreso mensual por persona entre 38 
dólares y 76 dólares en Boa Vista del Ita.

Los agentes del gobierno son responsables de la difusión y aplicación de políticas públicas en estas comunidades, dado que la mayoría de los residentes no son conscientes de sus derechos fundamentales. Así, el hecho de reclamar la tierra como quilombola se constituye en el acceso a la ayuda monetaria de estos programas de gobierno. Acciones que no dejan de ser marginales en el contexto de la extrema pobreza.

\section{EN REALIDAD: UN DIFÍCIL ACCESO A LOS ALIMENTOS}

Sin embargo, para que exista la seguridad alimenticia es necesario que antes haya la disponibilidad de alimentos, lo que no se produce en Boa Vista del Ita. Si tomamos como base la declaración de Trigo et al., 1989), el estado nutricional de una comunidad depende principalmente de la existencia y accesibilidad de los alimentos necesarios para la supervivencia.

Debido principalmente al vallado de las tierras por los ganaderos en Boa Vista del Ita, se ha puesto en peligro la seguridad alimenticia del pueblo. El cercado de las tierras ganaderas es la principal causa de la falta de espacio para la siembra y el cultivo de alimentos para consumo de las familias residentes. El acceso a los alimentos necesarios debe hacerse mediante la adquisición y la dependencia del mercado local. Dada la falta de ingresos suficientes para comprar alimentos, a menudo, las familias sobreviven con escasez alimenticia, viéndose obligadas a comprar alimentos baratos, lo que en general significa alimentos poco nutritivos y de mala calidad. Un producto que alcanza gran importancia en su consumo es el jugo artificial, de una variedad de sabores; estos se basan azúcar y colorantes sin valor agregado nutricional, y en general los niños son los que más consumen y acentúan la gravedad de su consumo. 


\section{PERCEPCIÓN DE LOS ALIMENTOS DESDE EL PUNTO DE VISTA DE LOS NIÑOS}

En el presente apartado daremos comentarios sobre los dibujos realizados durante el taller con los niños del pueblo. El taller contó con la presencia de 23 niños, de la franja de dos a doce años de edad, quienes dibujaron los alimentos que consumen a diario.

El pescado fue el alimento más dibujado, ya sea vivo en el río o en la sartén cocinado o sobre un plato listo para comer. Esto no es sorprendente, ya que, según Mendes (2006), el pescado, la harina de yuca y el açaí (jugo del fruto de una palmera) representan los alimentos fundamentales de la dieta de la región. Según el autor, estos alimentos a menudo representan la única opción para las familias de bajos ingresos. La composición de esta dieta es equilibrada en términos nutricios, ya que el pescado es una buena fuente de proteínas y calcio, el açaí es rico en hierro y otras vitaminas, y la harina de yuca es fuente rica en calorías.

En la comunidad, la pesca se ve amenazada por la falta de peces en el río Ita y los arroyos cercanos. Eso significa que los habitantes se ven obligados a comprar pescados de un residente que los consigue en el mercado más próximo y los revende localmente.

La salchicha fue el segundo alimento más dibujado. Observamos que se trata de un alimento ampliamente consumido, frita con huevos y mezclada con harina de yuca, es bastante común verla en el plato de la gente. A menudo se trata de un alimento industrializado con alta concentración de sodio, pero con precios más bajos, y una pequeña cantidad sirve para alimentar a varias personas.

La carne de la vaca también fue muy dibujada: cruda, en una sartén o ya cocida en una olla, es el alimento consumido en fin de semana o en ocasiones especiales. Puede ser comprada una vez a la semana cuando van al mercado a vender los productos o bien comprada a un marreteiro $^{11}$ (comerciante) que vende por ahí el alimento. 
La carne de cerdo no apareció en el dibujo de los niños, pero es un alimento popular en las fiestas, cumpleaños, bodas, barbacoas; no obstante, por no tener suficiente espacio en el terreno para la crianza de cerdos, solamente se compra el animal entero, en ocasiones festivas, tornándose en alimento importante para la socialización y fortalecimiento de los lazos locales de solidaridad.

Durante nuestra estancia de trabajo de campo fuimos invitados al cumpleaños de una de las más antiguas habitantes, ocasión en que fue ofrecida la carne de cerdo como plato principal, en una preparación de asado. La carne de cerdo asado también es ofrecida en la fiesta del patrono de la comunidad, San Antonio. Además, en varios relatos de los informantes, principalmente de los más viejos, afirman la importancia del cerdo comunitario que es abatido para la fiesta de San Antonio y ofrecido a los participantes para celebrar, por medio de ese alimento, la comunión y la solidaridad local.

Observamos que había solo un cerdo en la comunidad y este andaba suelto por todas las quintas y era alimentado con restos de comida por los habitantes de las casas donde pasaba. Cuando preguntamos de quién era el animal, nos dijeron que «el puerco era de la comunidad».

El pollo apareció con menor frecuencia: crudo, asado o en el refrigerador; es curioso, ya que, como se menciona en el apartado de actividades económicas, al menos unos diez residentes del pueblo trabajan en la empresa Frango Americano (Pollo Americano), lo que significa que compran el producto a un precio más bajo que el que habitualmente tiene en el mercado. A menudo, la familia que tiene uno de sus miembros como trabajador de la empresa Frango Americano hace la vez de distribuidor de pollo entre familias de amigos y parientes cercanos. Durante nuestra estancia observamos a muchas familias comiendo pollos preparados de diferentes maneras: a la brasa, al horno, cocido con patatas. La 
donación o intercambio de alimentos entre parientes es común, el movimiento de los alimentos que no se compran está directamente vinculado con las relaciones de parentesco.

El pan y los huevos fueron ampliamente dibujados. Son alimentos que se encuentran fácilmente en la comunidad, ya que la mayoría de los residentes crían pollos o gallinas para su propio consumo. Cabe destacar que una residente ha montado una pequeña panadería en su casa, donde ella produce los panes que se venden por la mañana y tarde.

Considerado como la base de la alimentación de los brasileños, los frijoles y el arroz, en general, fueron dibujados separados y han sido representados de forma moderada. La mayoría dibujó el arroz cocido en la olla. Sin embargo, de acuerdo con nuestras observaciones, son alimentos que se consumen a diario, a menudo durante el almuerzo del día a día se sirven el arroz, la harina de yuca y frijoles, estos se cocinan con pequeños trozos de carne salada para darles sabor.

La mayoría de los dibujos hacen referencia a la tarta de cumpleaños; con velas, bolas pintadas de colores que representan los confites. Cuando se les preguntó si a menudo comían pastel, respondieron que cuando hay cumpleaños sí. La tarta es considerada por ellos un alimento precioso, buenísimo, exquisito, escaso y exclusivo de las fiestas de niños, porque la mayoría de las casas no tienen un horno de gas. Los residentes cocinan los alimentos en el fogón de leña, lo cual consideran rudimentario. Según Senra (1996), las dietas alimenticias son utilizadas como idiomas de diferenciación; en el caso citado, diferenciación interna y generacional que marca un grupo de edad, dejando ver en este caso al pastel como el alimento deseado particularmente por los niños y no tanto por los adultos.

\section{MANDIOCA: LA BASE DE LAALIMENTACIÓN}

Algunos investigadores brasileños (Mendes, 2006) afirman que Pero Vaz de Caminha fue uno de los primeros en escribir acerca de la alimentación en Brasil, en la famosa carta al rey 
de Portugal en el año 1500, en la que describe que los indígenas no criaban animales ni cultivaban; sin embargo, consumían bastante yuca, que había en grandes cantidades en el suelo brasileño, así como semillas y frutos.

Diegues Junior (1972) afirma que para las etnias indígenas que practicaban la agricultura, el alimento más importante era la mandioca. Según Schaan (2010), fueron los tupis los responsables de la difusión de la mandioca en América del Sur. De acuerdo con Algranti (1997), en las actividades ligadas a la alimentación, el proceso de fabricación de la harina de mandioca fue uno de los que más llamó la atención a los viajeros extranjeros al Brasil en los siglos XVI y XVII. Estos registraron detalladamente el proceso de obtención de la harina, en tanto que representaba el equivalente y sustituto del pan de trigo en la alimentación de los portugueses que vivían en Brasil. Su elaboración era considerada una actividad «típicamente femenina».

Por supuesto, en la actualidad la harina de mandioca sigue siendo un importante alimento para la población rural de la Amazonia brasileña. Así lo constatamos al pedir a los niños que dibujaran los alimentos obtenidos por medio de compra o directamente en el campo. Sin duda, el alimento más representado fue la yuca, obviamente porque la harina es el alimento local por excelencia, que no puede faltar en ninguna comida.

La mayoría de los niños dibujaron la yuca, seguida de la mandioca (otra especie de yuca) y la maniva (hojas de la yuca). Fueron representados también el maíz y la sandía, pero con menos frecuencia. Un niño dibujó a una pareja que cultivaban la tierra, representando a sus abuelos, quienes cosechaban la yuca y rallaban la mandioca. Otra niña dibujó un hombre tostando la harina de yuca.

La representación de la yuca y la elaboración de la harina fueron frecuentes, ya que, como mencionamos anteriormente, la plantación de la yuca es la actividad principal en los campos de cultivo, y transformándola en harina pasa a ser la principal base la alimentación 
de los residentes de Boa Vista del Ita y también de su economía, pues sirve tanto para el consumo familiar como para la venta.

Durante nuestra estancia de campo observamos que durante toda la semana el grupo familiar se dedica a la elaboración de la harina de yuca. La venta de la harina, la goma (almidón) y del tucupi representan una fuente importante de ingresos para las familias locales.

Según Castro (1965), la harina de yuca es el alimento básico de los pueblos de la Amazonia. En Boa Vista del Ita, los residentes incluso comen la harina de yuca mezclada con el café en el desayuno. El pan es un alimento introducido recientemente en la comunidad. Asimismo, Mendes (2006) señala que, durante todo el proceso de la colonización de Brasil, la yuca fue el alimento básico de los brasileños en las situaciones de crisis alimentarias y la garante de la supervivencia de muchos habitantes, y al día de hoy sigue siendo un alimento indispensable para la alimentación de las personas, principalmente en las regiones tropicales de muchos pueblos del mundo entero. Para la autora, «Los múltiples y variados aspectos que se presentan con respecto al cultivo y explotación en general no solo le remarcan su importancia social, sino también en lo económico y en su dimensión histórica» (2006:36).

Al estudiar un Quilombo agrícola bahiano ${ }^{12}$ de 1800, el historiador Reis (1996) afirma que este mantenía importantes relaciones económicas con el mercado regional por abastecerlo de harina de mandioca, la cual era considerada el «pan de la tierra», ya que no solo era el alimento más común en los hogares bahianos, sino también el de las flotas que mantenían comercio con África y Portugal. Podemos ver entonces que la harina de mandioca ya era importante para la supervivencia tanto de los quilombos antiguos como de los contemporáneos. 
Según Alencastro (2000), después de la introducción de la mandioca en el continente africano, esta pasó a ser cultivada en grandes escalas en Brasil -muy probablemente su región de origen-, para luego ser exportada a África, transformándose en el principal alimento del dinámico comercio esclavista. De este modo la mandioca se constituye en uno de los principales factores de articulación de la economía en el Atlántico sur. Si enfatizo la importancia de la cultura de la mandioca en la historia es para mostrar el papel sumamente fuerte que todavía ejerce en la economía de las comunidades agrícolas de la Amazonia.

\section{ALIMENTOS COMPRADOS EN EL PLATO DE LOS QUILOMBOLAS}

La mayor variación de alimentos dibujados se dio en los obtenidos por compra; por ejemplo: salchichas, mortadela, galletas, café, frijoles, arroz, carne, pollo, leche, calabaza y uva. Woortman (1978) establece que los hábitos alimentarios se construyen a partir de diferentes estrategias de consumo y pueden tener en cuenta no solo los alimentos consumidos, sino también otras consideraciones como las condiciones disponibles para que sean consumidos, el acceso a alimentos capturados localmente, así como su adquisición a través la compra.

Anteriormente se hacía una relación entre el alimento adquirido y el ingreso solo en los centros urbanos; sin embargo, actualmente las zonas rurales también se incluyen cada vez más por depender de los mercados y de la adquisición de alimentos por compra, lo que provoca cambios en los hábitos alimentarios de las poblaciones rurales. En la construcción de estos hábitos, de acuerdo con Mintz (2001), tanto los viejos como los modernos hábitos se fundieron para formar las prácticas alimenticias de un pueblo, ya que muchas veces las opciones pueden ser reducidas por la dificultad en el acceso a los alimentos.

\section{INSEGURIDAD ALIMENTICIA}

La situación de inseguridad alimenticia experimentada por los residentes de Boa Vista del Ita puede ser destacada por el dibujo de Eduarda dos Santos, de siete años, quien dibujó una 
gran casa, con paredes pintadas de verde y techo rojo, y dijo que no había comida en ella. Durante nuestra estancia en el campo se observó que algunas familias pasaban situaciones de carencia de alimentos, donde la harina de yuca era el único elemento disponible. Además de esta situación y como ya señalamos antes, debe considerarse que hay un número importante de familias que no tienen acceso a alimentos de calidad ni cantidad suficiente para promover una dieta adecuada y sana.

Cuando no tienen nada para comer en Boa Vista recurren al chivé, plato preparado con harina de mandioca, agua y sal. Dado que la harina de mandioca es elaborada localmente, es el único alimento que mantiene su disponibilidad en periodos de fuerte escasez alimenticia en la comunidad.

Durante el proceso de fabricación de la harina, mientras descascarábamos la mandioca, una de nuestras interlocutoras en un relato espontáneo, aunque con una voz un poco ahogada, contó que en cierta ocasión casi todas las familias de la comunidad estuvieron con escasez de alimentos y, como ya hacía varios días que no consumían ninguno, decidieron hacer un guisado de harina gigante en una gran olla, cocido en una fogata enmedio de la comunidad. De esta manera todos pudieron alimentarse. Se percibe, así, que la harina es la caloría más barata que se puede adquirir localmente.

\section{A MODO DE CONCLUSIÓN}

En Boa Vista, la mandioca era en el pasado y hoy en día es el principal alimento local. Aunque antiguamente, por el mayor espacio que tenían para plantarla, no se compraba a terceros. Pudimos observar en el transcurso de algunas entrevistas cómo los interlocutores nos hablaban de la mandioca como un elemento importante de sus actividades económicas. En sus declaraciones, la alusión a la harina de mandioca era frecuente, sea rememorando el «tiempo antiguo», cuando la comían con los peces que sacaban del río o con otros animales 
que cazaban en los matorrales aledaños -hoy extinguidos para dar lugar a las haciendas-, o en la actualidad, como único alimento disponible.

Ahora, los residentes en Boa Vista del Ita viven una fuerte dependencia alimenticia por el abastecimiento del mercado. Esta población tiene bajos ingresos y está ligada a una producción local de subsistencia netamente insuficiente. Además, el medio ambiente que contribuye a su alimentación se encuentra muy alterado. Los factores principales que causan esta situación son la falta de tierra para sembrar y la titulación de las mismas. Esto acentúa las condiciones de inseguridad alimenticia y la incertidumbre sobre el futuro.

La consecuencia es la reducción de una parte de los alimentos producidos o recolectados localmente. Lo que conlleva un gran cambio en su modo de vida y en el consumo de alimentos, que cada vez más son comprados en el mercado, lo cual provoca cambios en la alimentación, en las prácticas alimenticias mismas y en las representaciones de la vida cotidiana.

Finalmente, señalamos nuestra coincidencia de opinión con Katz y Sureiman (2008), al considerar la alimentación como uno de los medios por el que se desarrollan identidades colectivas e individuales, en la medida en que la alimentación de las personas de una determinada sociedad puede constituir un sistema de representación, conocimientos y prácticas relevantes para la comprensión de los grupos sociales. 


\section{BIBLIOGRAFÍA}

Alencastro, Luiz Felipe, 2000, O trato dos viventes. Formação do Brasil no Atlântico Sul, séculos XVI e XVII, Companhia das Letras, São Paulo.

Algranti, Leila Mezan, 1997, «Familias e Vida Doméstica», en História da vida privada no Brasil v.1: Cotidiano e vida privada na América portuguesa, compilado por Novais, Fernando et Mello y Laura Souza, Companhia das Letras, São Paulo, pp. 84-154.

Beraldo, Neide Aparecida da Silva, 2006, «Saberes e práticas alimentares dos agricultores quilombolas da comunidade Maçambique», en Prêmio ABA/MDA Territórios Quilombolas / Associação Brasileira de Antropologia, compilado por Ministério do Desenvolvimento Agrário, Núcleo de Estudos Agrários e Desenvolvimento Rural, Brasilia, pp. 97-118.

Bonin, Ana Maria Aimoré y Maria do Carmo Rolim, 1991, «Hábitos Alimentares», en Boletim de Antropologia, v. 4, n.1, Curitiba, pp. 75-90.

Bosi, Éclea, 1994, Memória e sociedade: Lembranças de velhos, Companhia das Letras, São Paulo.

Brasil, 1988, Constituição Federal, Senado Federal, Brasilia.

Castro, Josué 1965, Geografia da fome, Brasiliense, São Paulo.

Conde, Renilda Borges de, 1999, «A intervenção de órgãos públicos na comunidade negra de Boa Vista do Itá», Tesis de maestría, NAEA/Universidade Federal do Pará/UFPA, Belém. 
Costa, Marcilene Silva da y Marjorie Ruffeil, 2009, Informe de Campo Comunidade quilombola Boa Vista do Itá: na memória a afirmação de identidades e busca pelos direitos, Universidade Federal do Pará/UFPA, Belém.

Cunha, Manuela Carneiro da, 2010, «A querela das terras de quilombos», en Folha de São Paulo, Tendência/Debates, 26 de mayo, São Paulo.

Debert, Guita G., 1986, «Problemas relativos à utilização da história de vida e história oral», en A aventura antropológica: teoria e pesquisa, compilado por Cardoso, Ruth, Paz e Terra, Rio de Janeiro.

Diégues Júnior, Manuel, 1972, Etnias e culturas no Brasil, Editorial Paralelo, Instituto nacional do livro, Rio de Janeiro.

Figueiredo, Aldrin Moura de, 1996, «A cidade dos encantados: pajelança, feitiçarias, e religiões afro-brasileiras na Amazônia; a constituição de um campo de estudo; 1870-1950», Tesis de maestria, UNICAMP, Campinas.

Katz, Esther y Suremain, Charles-Édouard, «Introduction: modèles alimentaires et recompositions sociales en Amérique Latine», Anthropology of food, núm. 4, mayo 2008, en http://aof.revues.org/index4033.html (consultado el 19 abril de 2010).

Mendes. Patricia, 2006, «Segurança alimentar em comunidades quilombolas: estudo comparativo de Santo Antônio (Concórdia do Pará) e Cacau (Colares), Pará», Tesis de maestría, Universidade Federal do Pará/UFPA, Belém.

Mintz, Sidney W, 2001, «Comida e antropologia uma breve revisão», em Revista Brasileira de Ciências Sociais, v. 16, n 47, São Paulo. 
Reis, João José, 1996, «Escravos e coiteros no quilombo de Oitizeiro-Bahia, 1806», en Liberdade por um fio. História dos Quilombos no Brasil, compilado por Reis, João José y Flavio Gomes, Cia das Letras, São Paulo.

Salles, Vicente, 1988, O negro no Pará sob regime de escravidão, FGV, Belém.

Schaan, Denise, 2010, «Deixando a terra natal: as migrações pré-colombianas», en Migrações na Amazônia, compilado por Cancela, Cristina y Rafael Chambouleyron, Açaí/Centro de Memoria da Amazônia/PPGA, Belém, pp. 9-26.

Senra, Klinton, 1996, «Gente é Macaco de Onça. Padrões de Comestibilidade de Animais nas Terras Baixas da América do Sul», Tesis de maestria , Museu Nacional, Río de Janeiro.

Torrão, Maria Manuel, 1995, «Alimentação da População das Ilhas de Cabo Verde: a permanência dos hábitos alimentares», en Dietas Alimentares. Transferências e Adaptações nas Ilhas de Cabo Verde (1460-1540), Instituto de Investigação Científica Tropical, Lisboa.

Trigo, Marlene et al., 1989, «Tabus Alimentares em Região do Norte do Brasil», Revista Saúde Pública, v. 23, n. 6, São Paulo, pp.455-464.

Woortmann, Klaas, 1978, Hábitos e ideologias alimentares em grupos sociais de baixa renda -Relatório Final, Universidad de Brasilia, Serie Antropológica 20, Brasilia. 


\section{NOTAS}

${ }^{1}$ Población formada por esclavos negros fugitivos.

${ }^{2}$ Constitución Federal: Brasilia: Senado Federal, 1988: 169.

${ }^{3}$ Véase: http://www.koinonia.org.br/oq/quilombo.asp. Consultado el 15/04/2010.

${ }^{4}$ Organismo regional responsable de la aplicación de la política de tierras agrarias en el estado del Pará. Celebra convenios con el Instituto de Colonización y Reforma Agraria (INCRA), el organismo federal responsable de la expedición de títulos de tierras de propiedad colectiva de los descendientes de quilombos.

${ }^{5}$ En Brasil, los apellidos maternos preceden a los paternos en la disposición del nombre completo.

${ }^{6}$ Actualmente, el distrito de Caraparu se caracteriza por ser una ciudad turística popular importante, teniendo uno de los más populares balnearios turísticos de la ciudad.

${ }^{7}$ Sinónimo de quilombo en la designación de la región.

${ }^{8}$ El proyecto tiene como objetivo investigar los hábitos dietéticos, enfermedades crónicas, el acceso al sistema de salud, historias y memorias, así como las percepciones identitarias quilombolas. El proyecto es financiado por el Consejo Nacional de Investigación y Desarrollo Científico Brasileño (CNPQ) y la universidad Federal de Para (UFPA). El proyecto es coordinado por el antropólogo JB. Véase: Costa, Marcilene Silva da y Marjorie Ruffeil, 2009, Informe de Campo Comunidad quilombola Boa Vista do Itá: na memória a afirmação de identidades e busca pelos direitos, Universidade Federal do Pará/UFPA, Belém.

${ }^{9}$ Nombre que se da al espacio físico donde se realiza la venta de productos; puede entenderse mercado, en el sentido de infraestructura.

${ }^{10}$ El salario mínimo en la época era de 255 dólares.

11 Designación para el revendedor de los productos alimenticios locales que utiliza una moto para moverse por la región con la venta de alimentos.

${ }^{12}$ Gentilicio para las personas del departamento de Bahía.

Fecha de recepción: 23 de febrero de 2011.

Fecha de aceptación: 16 de abril de 2012. 